Check for updates

Cite this: RSC Adv., 2017, 7, 47357

Received 3rd August 2017

Accepted 2nd October 2017

DOI: $10.1039 / c 7 r a 08578 h$

rsc.li/rsc-advances

\section{Mechanically robust, thermally stable, highly transparent superhydrophobic coating with low-temperature sol-gel process}

\author{
Yanping Zhang, ${ }^{\text {ab }}$ Binghai Dong, (iD *ab Shimin Wang, ${ }^{* a b}$ Li Zhao, $^{\text {ab }}$ Li Wan $^{\text {ab }}$ \\ and Erjing Wang ${ }^{\text {ab }}$
}

\begin{abstract}
The wetting behavior of transparent superhydrophobic surfaces has attracted much attention in our daily life as well as in engineering applications. Optically transparent superhydrophobic silica films were synthesized by sol-gel method. The coating was formed by in a solution containing silica nanoparticles and silicic acid, in which the silica nanoparticles and silicic acid had different proportions to modulate the roughness of the coating. Comparing with the HMDZ modified films $\left(140 \pm 2^{\circ}\right)$, the films modified by TMCS showed very high water contact angle $\left(164 \pm 2^{\circ}\right)$, which indicating the excellent waterproof behavior of the films. When the TMCS modified films were heated at temperature above $350{ }^{\circ} \mathrm{C}$ and $400{ }^{\circ} \mathrm{C}$, it became superhydrophilic. The transmittance of coated glasses were above $80 \%$ for wavelengths at $400-800 \mathrm{~nm}$. Moreover, the properties of the film were almost unchanged after acid corrosion and immersion in salt solution, and still retained the superhydrophobicity. Even after the impact of water flow and sand impact abrasion, it can still maintain good performance of superhydrophobicity.
\end{abstract}

\section{Introduction}

An excellent non-wetting surface that exhibits a contact angle (CA) above $150^{\circ}$ and sliding angle (SA) below $10^{\circ}$ is referred to as a superhydrophobic surface. ${ }^{1-4}$ Surface wettability is one of the most important properties of solid surfaces. It is closely related to basic science theory and practical applications. The phenomenon that water droplets cannot adhere to such a surface but roll off is advantageous for potential applications in self-cleaning, ${ }^{5,6}$ anti-fogging, ${ }^{7,8}$ oil-water separation,, ${ }^{\mathbf{9}, 10}$ and anti-icing. ${ }^{11,12}$ Transparent superhydrophobic surfaces expand the range of potential applications to optical fields such as windshields for automobiles, solar-cell panels, safety goggles, and windows for electronic devices, ${ }^{13-15}$ and therefore have recently attracted more and more attention. Recently, the increasing interest in energy efficiency has prompted research in developing coatings that are both selfcleaning and transparent. ${ }^{16-24}$ For example, the desire for alternative energy sources has made significant progress in the development of solar cells. However, the build up of dust, dirt, pollution, wet-snow, tree saps and bird droppings on the surface of the solar panels can block the sunlight from reaching the solar cells, therefore, dramatically decreasing the efficiency and output of the solar energy. Transparent, superhydrophobic coating will

${ }^{a}$ Hubei Collaborative Innovation Center for Advanced Organic Chemical Materials, China.E-mail:wwwdbh@163.com; shiminwang@126.com

${ }^{b}$ Key Laboratory for the Green Preparation and Application of Functional Materials, Ministry of Education, Hubei Key Laboratory of Polymer Materials, Faculty of Materials Science and Engineering, Hubei University, Wuhan 430062, PR China also be very useful for the protection of buildings, clothes, papers, and art pieces.

Accordingly, the synthesis of superhydrophobic films requires the combination of surface chemical modification and the enhancement of surface roughness. Since the microscopic structure of superhydrophobic coatings strongly scatter visible light, high transparency in the visible region and superhydrophobic properties are mutually exclusive in principle. Increasing the surface roughness can enhance the hydrophobicity, but reduce the transparency due to light scattering losses. Mie scattering is responsible for the blurring of superhydrophobic surfaces. ${ }^{22}$ In order to minimize Mie scattering, surface roughness must be reduced below the wavelength of incident light. Sub-100 nm with lower scattering intensity has been proved to be able to prepare superhydrophobic surfaces with high visible light transparency. Therefore, in order to make transparent superhydrophobic surfaces, particular attention should be paid to controlling the surface roughness size. Therefore, controlling the surface roughness to an appropriate value is the main task to meet the both of requirements. ${ }^{25-27}$

The practical application of superhydrophobic surfaces was limited by some preparation conditions, multi-step processes, expensive low surface energy materials, etc. Most of the barefluorinated materials have the expensive price and often are vulnerable to environment attacks while causing ozone shield to crack more seriously. Hence, the other hydrophobic group must be replaced for good use. Whereas fluorine-containing bonds $\left(-\mathrm{CF}_{3}\right)$ have lower surface tension than $-\mathrm{CH}_{3}$, replacing $-\mathrm{CF}_{3}$ with $-\mathrm{CH}_{3}$ chemistries need introducing more stringent 
requirements for transparent superhydrophobic surface. ${ }^{28}$ It is usually introduced as supplementary end-capping by means of trimethylchlorosilane (TMCS) and hexamethyldisilazane $(\mathrm{HMDZ})^{29}$ for modifying the hydrophilic groups to enhance hydrophobic properties of the as-prepared surfaces.

Recently, many artificial surfaces have been investigated with regard to their chemical, mechanical, ${ }^{\mathbf{1 9}, 30}$ and thermal stability. ${ }^{31}$ A 10 min of ultrasonication damage on a superamphiphobic coating resulted in a rapid decrease in the contact angle and an increase in the contact angle hysteresis. ${ }^{32}$ Deng et $a .^{24}$ reported a simple way to fabricate robust transparent superamphiphobic coatings using candle soot as template followed by ammonia-catalyzed CVD of tetraethoxysilane (TEOS). The coatings could withstand water-drop impact, sand abrasion test and tape peeling test. Yokoi et al. ${ }^{33}$ sprayed $1 \mathrm{H}, 1 \mathrm{H}, 2 \mathrm{H}, 2 \mathrm{H}^{-}$ perfluorooctyl-triethoxysilane (PFOTS) modified $\mathrm{SiO}_{2}$ nanoparticles onto a polyester mesh, which had been etched by alkaline followed by CVD of $1 \mathrm{H}, 1 \mathrm{H}, 2 \mathrm{H}, 2 \mathrm{H}$-perfluorodecyltrichlorosilane (PFDTS), obtaining a highly transparent superhydrophobic thin film. The thin film showed enhanced abrasion resistance. Undoubtedly, the mechanical stability, especially the adhesive strength between the coating and the substrate determines the application of the coating. In most cases, however, high-temperature treatment was commonly used to enhance the robustness of thin films, which limits their practical applications on most polymer substrates having low glass transition or decomposition temperatures and being unable to withstand any high-temperature treatment. For industrial implementation, the coatings must be easily fabricated at low energy consumptions and must be durable during services. Moreover, the improvement of mechanical robustness was mostly at the expense of high transmittance and superhydrophobicity. Therefore, the coatings via a low-temperature fabrication having superhydrophobic characteristic and possessing mechanical stability of anti-acid/alkali damage and water flow impact and sand impact abrasion are less well studied so far. ${ }^{16,24,32}$

In this study, a durable transparent superhydrophobic $\mathrm{SiO}_{2}$ based coating was processed onto glass substrates by a sol-gel process at low-temperature. $\mathrm{SiO}_{2}$-based surfaces went through the conversion of the hydrophilic surface to superhydrophobic $\left(\mathrm{CA}>150^{\circ}\right)$ by $\mathrm{TMCS}$ derivatization and in ultra hydrophobic $\left(\mathrm{CA}>120^{\circ}\right)$ by HMDZ derivatization. Moreover, the obtained coating exhibited stable superhydrophobicity under extreme conditions of low or high temperature, water flow impact and sand impact abrasion. The formation of nonfluorinated superhydrophobic surfaces at low temperatures is important for the fabrication of environmentally friendly coatings.

\section{Experimental sections}

\subsection{Materials}

Tetraethoxysilane (TEOS, 98\%), ethanol, $n$-hexane, hydrochloric acid ( $\mathrm{HCl}, 36-38 \%)$, silica dioxide $\left(\mathrm{SiO}_{2}, 98 \%\right.$, average diameter $15 \pm 5 \mathrm{~nm}$ ) trimethylchlorosilane (TMCS, 97\%) 1,1,1,3,3,3-hexamethyldisilazane (HMDS, 98\%) were purchased from Aladdin Industrial Co., Ltd. All chemicals were analytical grade reagents and were used without further purification. Deionized water (resistivity $\sim 18 \mathrm{M} \Omega \mathrm{cm}$ ) was used in this study.

\subsection{Preparation of silica solution}

The coating solution was prepared by the sol-gel method using $\mathrm{HCl}$ aqueous solution as the catalyst. ${ }^{34}$ In a typical production, hydrochloric acid was added to deionized (DI) water for preparing $(\mathrm{pH}=2) \mathrm{HCl}$ aqueous solution. TEOS and $(\mathrm{pH}=2) \mathrm{HCl}$ aqueous solution were mixed together at a molar ratio of $1: 4.6$ with a magnetic stirrer for $2 \mathrm{~h}$, giving rise to silicic acid, $\mathrm{Si}(\mathrm{OH})_{4}$. Then, $15 \mathrm{~nm}$ silica powders were dispersed in ethanol $(200 \mathrm{~mL})$ at different content using a magnetic stirrer and ultrasonic vibrator for $30 \mathrm{~min}$. Silicic acid was then added to the silica/ethanol solution using a magnetic stirrer and ultrasonic vibrator for $2 \mathrm{~h}$. The composition of each sol-gel solution are list in Table 1.

\subsection{Formation of superhydrophobic coating}

The substrate used for this study was transparent plain glass (microscope slides) of $25 \times 25 \times 1 \mathrm{~mm}$. A chemical substrate cleaning procedure was ultrasonicated for $30 \mathrm{~min}$ with $\mathrm{HCl}(0.1$ $\mathrm{M}), \mathrm{NaOH}(0.1 \mathrm{M})$, deionized water, ethanol and isopropylalcohol, respectively, in turn to remove the surface contamination and dust. All glass substrates were dried at $50{ }^{\circ} \mathrm{C}$ for $2 \mathrm{~h}$ before coating. In order to expose more hydroxyl to the surfaces of the glass, the clean glasses were placed in the UV cleaning machine for $20 \mathrm{~min}$. Then the uniform films were prepared at a spinning rate of $1000 \mathrm{rpm}$ for $9 \mathrm{~s}$ and $2500 \mathrm{rpm}$ for $30 \mathrm{~s}$ while spinning the mixing solution onto the clean substrates. All coating processes were conducted in ambient atmosphere (approximately $25^{\circ} \mathrm{C}, 70 \%$ relative humidity). And, all the coated glasses were allowed to cure at $80{ }^{\circ} \mathrm{C}$ for $4 \mathrm{~h}$, $120^{\circ} \mathrm{C}$ for $6 \mathrm{~h}$. This curing step was used to form a dense threedimensional structure by thermally-induced self-condensation reactions within the coating material as hydroxide groups were removed from the remaining silanol molecules, and the structure was bonded to the underlying substrate. Finally, the coated substrate by dipping in $4 \mathrm{v} / \mathrm{v} \%$ TMCS hexane solution by solvothermal method at $80{ }^{\circ} \mathrm{C}$ for $8 \mathrm{~h}$. Then all the coated glass substrates were annealed at $120{ }^{\circ} \mathrm{C}$ for $4 \mathrm{~h}$ to solidify the nanocoating and remove the unreacted solvent.

\subsection{Characterization}

The surface morphology of coating was examined by field emission scanning electron microscopy (FE-SEM, Jeol JEM, $6510 \mathrm{LV})$. The samples were coated with a thin gold layer to improve electrical conductivity before SEM observations. The samples for FT-IR characterization are prepared by removing

Table 1 The composition of sol-gel solution studied

\begin{tabular}{llll}
\hline Sr no. & Silica particle & Ethanol $(\mathrm{mL})$ & $\mathrm{Si}(\mathrm{OH})_{4}(\mathrm{~mL})$ \\
\hline 1 & $1.5 \mathrm{~g}$ & 200 & 3 \\
2 & $3 \mathrm{~g}$ & 200 & 6 \\
3 & $4.5 \mathrm{~g}$ & 200 & 9
\end{tabular}


film from the substrate by using stainless steel knife. Sample powder was mixed with $\mathrm{KBr}$ and a homogeneous mixture formed with a mortar and pestle, then scanned in frequency range from 450 to $4000 \mathrm{~cm}^{-1}$. X-ray photoelectron spectroscopy (XPS) was carried out on a Thermo Scientific K-alpha photoelectron spectrometer with the monochromatic $\mathrm{Al}-\mathrm{KCl}$ source to identify the chemical constituents. The transmission spectra of the coated glass substrate were obtained by a UV-vis spectrophotometer (UV-3600, Shimadzu). A atomic force microscope (AFM, Nanoscope-IIIa) was employed to get the information of surface roughness of film. Water contact angle (WCA) samples were measured at room temperature on the JC2000CS measuring instrument equipped with CCD camera. Each contact angle measurement was repeated three times at different places on each sample and the mean value was reported.

\section{Results and discussion}

\subsection{Reaction mechanism in preparation of transparent superhydrophobic coatings}

The fabrication process of the coating on the glass substrate is shown in Fig. 1. The first step of the whole process was hydrolysis of TEOS to form silicic acid. ${ }^{35}$ Since the condensation reaction of the silicic acid and $\mathrm{Si}(\mathrm{OH})_{4}$ is easy to carry out, the monomer silicic acid has never been isolated. The results showed that the monomer silicate was only in dilute aqueous solution. In addition, the behavior of silicic acid showed the maximum temporary stability in the absence of salt, and the gel time was the longest when the $\mathrm{pH}=1.5-3 .^{36}$ Therefore, by adding hydrochloric acid, the $\mathrm{pH}$ value of the TEOS and the excess deionized water can be controlled at 2 . Silica nanoparticles in ethanol solvents are dispersed in sol-gel solutions with the addition of the silicic acid due to the solvent effect. That is to say, silicic acid can cover the surface of silica by forming hydrogen bonds on the silicon substrate by pairs of $\mathrm{Si}-$

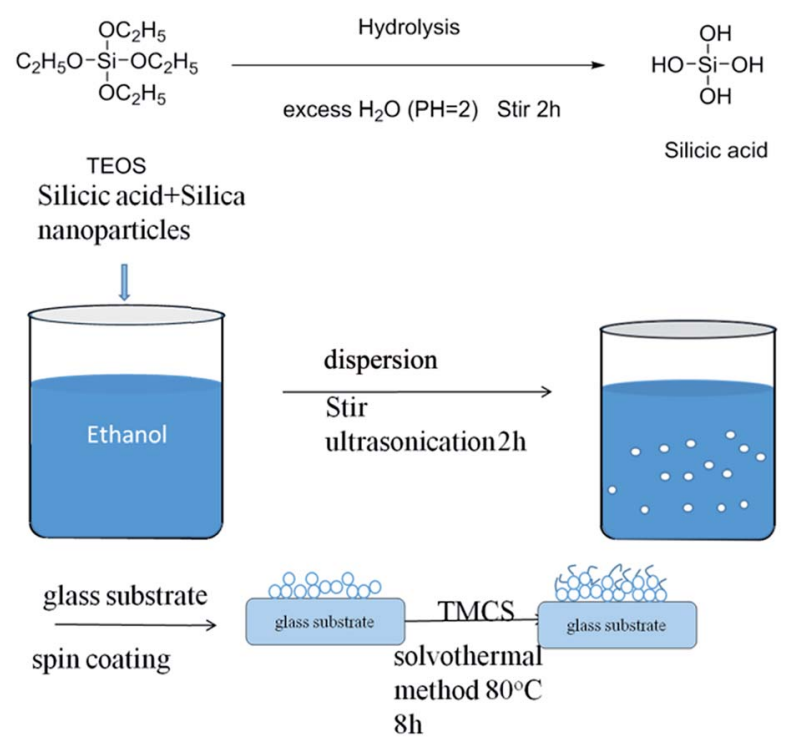

Fig. 1 Schematic representation of the approach to deposit a superhydrophobic coating on the glass substrate.
$\mathrm{OH}$ groups. When the sol-gel solution spreads on the glass substrate, the silica covered with the silicic acid was also attracted onto the glass substrate through hydrogen bond formation. Then, the hydrogen bond in a pair of $\mathrm{Si}-\mathrm{OH}$ groups transformed to the covalent bond of $\mathrm{Si}-\mathrm{O}-\mathrm{Si}$ through a baking dehydration process. Finally, the TMCS was deposited onto the rough silica-based film through dehydration during baking.

\subsection{Effect of different silylating agent and percentage of silylating agent}

In principle, the HMDZ and TMCS react with hydroxyl groups on the silica surface and could be represented by the following chemical reactions:

Surface modification by HMDZ:

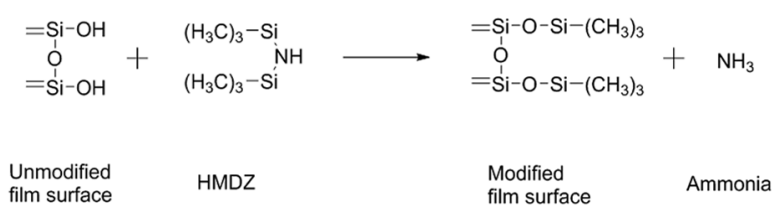

Surface modification by TMCS:

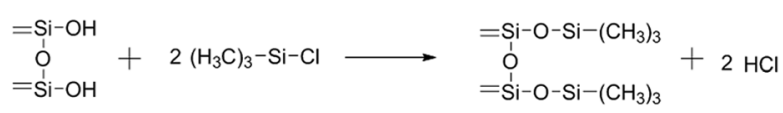

$\begin{array}{lll}\text { Unmodified } & \text { TMCS } & \begin{array}{l}\text { Modified } \\ \text { film surface }\end{array}\end{array}$

However, from the experimental observations, it seems that even if the nonpolar groups end-capping, the film surfaces are remain the same, while their physical and chemical properties will change in a wide range, depending on the nature of the used silicon agent. ${ }^{37}$

The content of $\mathrm{SiO}_{2}$ nanoparticles was varied from 1 to $3 \%$ keeping the silylation period constant at $8 \mathrm{~h}$. From the water contact angles of the hydrophobic films for different contents of

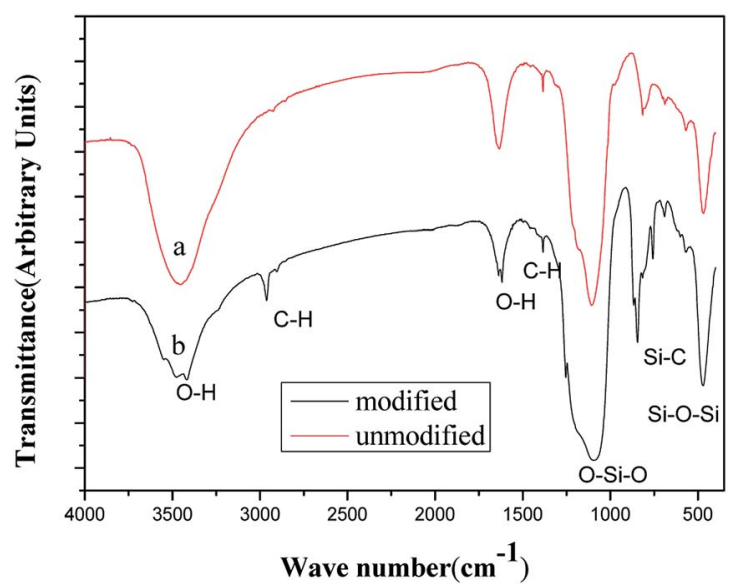

Fig. 2 FT-IR spectra of (a) unmodified silica film, (b) TMCS modified silica films. 
$\mathrm{SiO}_{2}$ nanoparticles given in Table 2, it could be seen that the contact angle increases with increasing in content of $\mathrm{SiO}_{2}$. However, for the TMCS modified-silica films, it observed that the contact angle increases from $140^{\circ}$ to $164^{\circ}$ with an increase in the content of $\mathrm{SiO}_{2}$. For the HMDZ modified silica films, it showed that with an increase in the content of $\mathrm{SiO}_{2}$, contact angle increases from $130^{\circ}$ to $148^{\circ}$. In addition to the above facts, it has been observed that the main cause of the difference in the physical properties of silica films are the different reaction kinetics of the silylating agents. In the case of TMCS, it can directly react with the silica surface to yield a nonpolar surface and $\mathrm{HCl}$ is given as a reaction product (eqn (5)). However, in the case of HMDZ the reaction mechanism shown by eqn (4) and may involve a two-step reaction as in the following; ${ }^{38}$

$$
\begin{aligned}
\equiv \mathrm{Si}-\mathrm{OH}+\mathrm{HN}\left(\mathrm{Si}-\left(\mathrm{CH}_{3}\right)_{3}\right)_{2} \rightarrow \\
\quad \equiv \mathrm{Si}-\mathrm{O}-\mathrm{Si}-\left(\mathrm{CH}_{3}\right)_{3}+\mathrm{H}_{2} \mathrm{~N}-\mathrm{Si}-\left(\mathrm{CH}_{3}\right)_{3} .
\end{aligned}
$$

Again the trimethylaminosilane, the byproduct of the above reaction can interact with the $\mathrm{Si}-\mathrm{OH}$ groups as shown in the following reaction;

$$
\equiv \mathrm{Si}-\mathrm{OH}+\mathrm{H}_{2} \mathrm{~N}-\mathrm{Si}-\left(\mathrm{CH}_{3}\right)_{3} \rightarrow \equiv \mathrm{Si}-\mathrm{O}-\mathrm{Si}-\left(\mathrm{CH}_{3}\right)_{3}+\mathrm{NH}_{3} \text {. }
$$

This indicates that the reaction rate of HMDZ with the silica surface is low as compared to the TMCS.

\subsection{FT-IR spectra analysis and XPS spectra of silica-based nanocoating before and after TMCS modification}

The chemical composition of the films deposited on a glass substrate was investigated by the FT-IR spectroscopy using the $\mathrm{KBr}$ method in transmission mode. The FT-IR spectra of the as bare silica and TMCS (4\%) modified films are shown in Fig. 2(a) and (b). The FT-IR spectra of the films should have been due to the hydrolysis of methoxy groups of the TEOS monomers to make $\mathrm{Si}-\mathrm{OH}$ groups, the polymerization of the $\mathrm{Si}-\mathrm{OH}$ groups to make the siloxane bonds and during the surface modification, the $-\mathrm{H}$ 's of the surface $\mathrm{OH}$ 's of silica films are replaced by $-\mathrm{Si}-$ $\left(\mathrm{CH}_{3}\right)_{3}$ groups resulting in dehydroxylation of the film surface leading to hydrophobicity. The absorption band of the $-\mathrm{OH}$ around $3400 \mathrm{~cm}^{-1}$ and that of water adsorbed around $1600 \mathrm{~cm}^{-1}$ are decreased after modifying the surface with TMCS. ${ }^{39}$ The FT-IR spectra of unmodified and TMCS modified silica films shows a very strong absorption band at $1096 \mathrm{~cm}^{-1}$ is

Table 2 The water contact angle of the silica films for different contents of $\mathrm{SiO}_{2}$ nanoparticles keeping silylation period constant at $8 \mathrm{~h}$ and keeping constant percentage (4\%) of HMDZ and TMCS

\begin{tabular}{llll}
\hline Sr no. & Content of $\mathrm{SiO}_{2}$ & $\begin{array}{l}\text { Effect of HMDZ } \\
(4 \%) \text { on WCA }\end{array}$ & $\begin{array}{l}\text { Effect of TMCS } \\
(4 \%) \text { on WCA }\end{array}$ \\
\hline 1 & $1 \%$ & $130^{\circ}$ & $140^{\circ}$ \\
2 & $2 \%$ & $142^{\circ}$ & $154^{\circ}$ \\
3 & $3 \%$ & $148^{\circ}$ & $164^{\circ}$
\end{tabular}

due to the stretching vibration of Si-O-Si bridges. ${ }^{40}$ The absorption bands observed at around $1400 \mathrm{~cm}^{-1}$ is due to stretching and bending of $\mathrm{C}-\mathrm{H}$ bonds and the peaks observed at $847 \mathrm{~cm}^{-1}$ are due to the $\mathrm{Si}-\mathrm{C}$ bonds. ${ }^{41}$ The number of $\mathrm{C}-\mathrm{H}$ and $\mathrm{Si}-\mathrm{C}$ peaks are quite notable for the TMCS modified films, which are found to be less for the unmodified silica. The $\mathrm{Si}-\mathrm{OH}$ band present in all the FT-IR spectra reveals that surface hydroxyls still exist, even though the materials show the strong hydrophobic behavior. In order to further elaborate the superhydrophobic mechanism of TMCS modified coatings, the chemical composition of TMCS modified coatings and unmodified coating were examined through XPS analysis (showed on Fig. 3). The surface atomic ratios of silica before and after TMCS treatment, summarized in Table 3, were calculated from peak area ratios. After treated by TMCS, the surface atomic ratio of $\mathrm{C}$ increases from $17.7 \%$ to $53.38 \%$, while the surface atomic ratios of $\mathrm{Si}$ and $\mathrm{O}$ decrease from $28.47 \%, 53.83 \%$ to $10.8 \%, 35.83 \%$, respectively. The results summarized in Table 3 are in good conformity with the conclusion of XPS spectra above. This high concentration of carbon endues TMCS modified coatings with a low surface energy in conjunction with hierarchical structure that entrusts their superhydrophobicity.

\subsection{Micrographs analysis of the various silica coatings modified by TMCS}

A scanning electron microscopy (SEM) image of the surface topology obtained with different content modified-silica nanoparticles containing layer is shown in Fig. 4. As is clearly visible, two different levels of nano texturing are present, being a key characteristic in the creation of
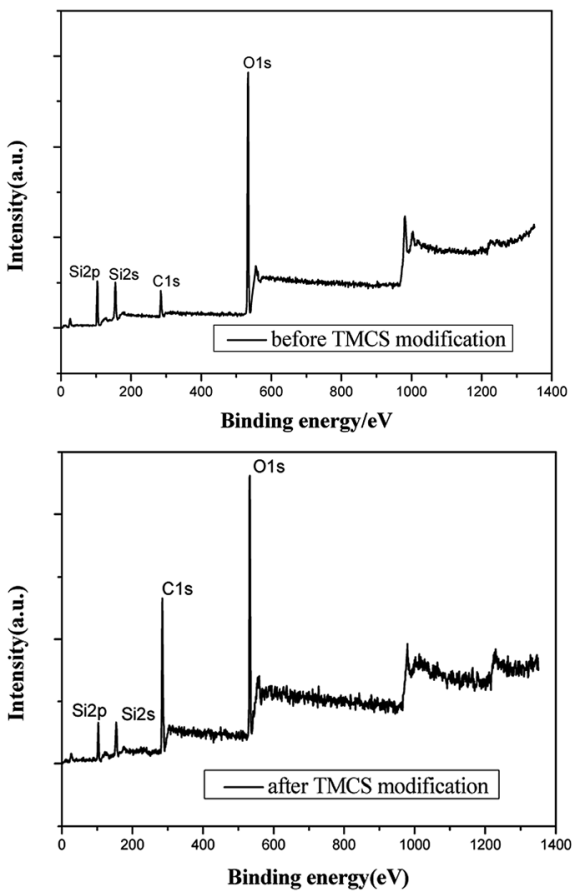

Fig. 3 XPS spectra of silica before and after TMCS treating. 
Table 3 The surface of atomic ratios of silica before and after TMCS treatment

\begin{tabular}{llll}
\hline Atomic ratio & $\mathrm{C} 1 \mathrm{~s}$ & $\mathrm{O} 1 \mathrm{~s}$ & $\mathrm{Si} 2 \mathrm{p}$ \\
\hline Before TMCS treatment & $17.7 \%$ & $53.83 \%$ & $28.47 \%$ \\
After TMCS treatment & $53.38 \%$ & $35.83 \%$ & $10.8 \%$ \\
\hline
\end{tabular}

superhydrophobic surfaces. As shows on Fig. 4, different content of $\mathrm{SiO}_{2}$ coating surface has similar apparent morphology, in addition, the density of coating on the surface film is unique because of the different content. From Fig. 4 as we can see, the percentage of $1 \mathrm{wt} \%$ of the silica coating surface has some bare place, which is failed to completely cover the glass surface. And the surface roughness is small, thus causing the surface contact angle is smaller. By contrast, the percentage of $2 \mathrm{wt} \%$ and $3 \mathrm{wt} \%$ of the coated surface formed a relatively dense thin film, causing the surface roughness increased with the increase of content, while accompanying with increasing contact angle. As Fig. 4(d) shows, the coating surface is made up of dozens of nano silicon dioxide particles unordered accumulated, it forms a range of roughness of micro-nano structure of the porous layer, which is the necessary conditions for forming superhydrophobicity. It is easy to understand that this behavior is related to the film morphology and the intrinsic low surface energy of silica particles, which originates from the chemical properties of the trimethyl groups grafted onto the surface of the particles. These species produce asymmetric molecular forces that cause water repulsion. To better reveal the effect of surface texturing on ultra water repellency, an AFM characterization (from Fig. 5) has also been done, it can be observed from the 2D AFM images that the surfaces of both substrates have been coated homogeneously by
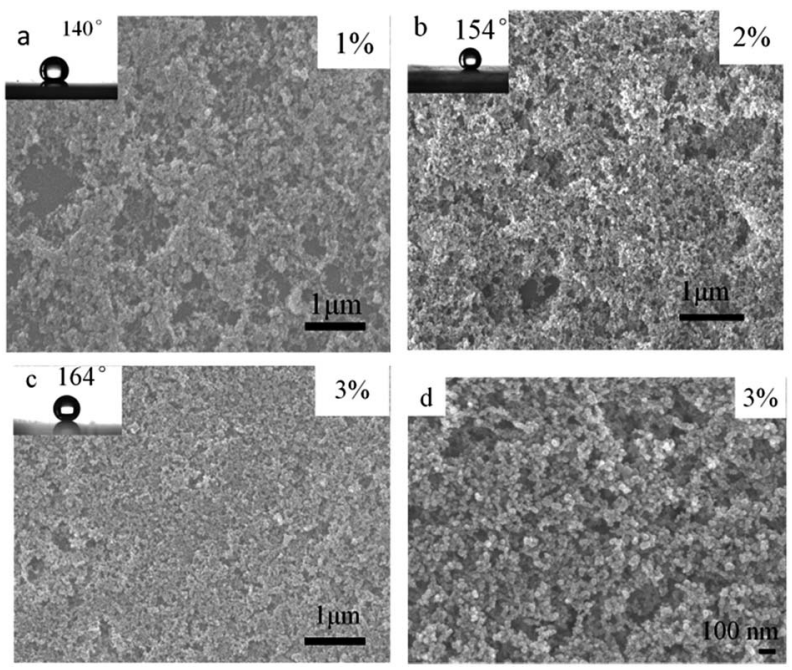

Fig. 4 SEM images of superhydrophobic coating, (a) spin coating of 1 wt\% silica solution, (b) spinning coating of 2 wt\% silica solution, (c) spinning coating of $3 \mathrm{wt} \%$ silica solution, scale bar $1 \mu \mathrm{m}$. (d) Highresolution SEM image of the $3 \mathrm{wt} \%$ coating. Scale bar $100 \mathrm{~nm}$. spinning coating, the height profile curves verify the results of 3D AFM images, from which frequently fluctuant height profiles can be seen for different content silica-coating. The rms roughness value of different content silica-coating can be calculated from the software, the rms roughness values were increased with the silica content. And all the rms roughness values $(\sim 40-90 \mathrm{~nm})$ are sub-100 $\mathrm{nm}$ roughness. It can be deduced that silica nanoparticles which deposit different content are responsible for the hierarchical roughness. The result is corresponding with SEM.

\subsection{Transparency measurement of silica-based film modified by TMCS}

Transparency is an important feature of superhydrophobic surface; for example, transparent films are the basic requirement when superhydrophobic surface are applied to windows and solar cells. However, the preparation of transparent superhydrophobic films is not simple, because surface roughness leads to a decrease in transparency due to the scattering of Mie. Therefore, in order to avoid the surface roughness caused by fuzzy, one should accurately control the surface roughness, surface roughness must be large enough to show the superhydrophobicity, but should be as low as possible to maintain transparency. These stringent limitations make it difficult to prepare superhydrophobic and transparent films on glass substrates. The transmittance is related to refraction of a transparent medium by the Fresnel's equation and the index of refraction of a material is related to its density. ${ }^{42}$ Optical characteristics of such coated superhydrophobic surfaces have also been tested by means of transmittance measurements. In Fig. 6 the transmission spectra of several coated samples are reported and compared to the spectrum of an uncoated sample. From Fig. 6(a), the transmittance of surfaces coated with different content silica nanoparticles is decreased with the increasing of content silica nanoparticles. These decrease in transmittance when compared with uncoated substrate is due to the deposition of silica nanoparticles with roughness greater than the uncoated glass, which leads to Mie scattering effect. In addition to surface roughness, the constituents and thickness of the film may also be the determining factor of transparency. It can be seen the relationship of transmittance and thickness from Fig. 6(b). The good readability of the script underneath the coated glass substrates reflected their high transparency, and the superhydrophobicity is demonstrated by almost sphere blue-colored water droplets in Fig. 7. In our coatings, the surface structure is a composite consisting of air and solid components. Therefore, a proper model was employed using effective medium approximation to calculate refractive index (RI) as follows: ${ }^{43}$

$$
\frac{n^{2}-1}{n^{2}+2}=k \frac{\left(n_{1}^{2}-1\right)}{\left(n_{1}^{2}+2\right)}
$$

The reflectivity is explained with Fresnel equation:

$$
R=\left(\frac{n-1}{n+1}\right)^{2}
$$



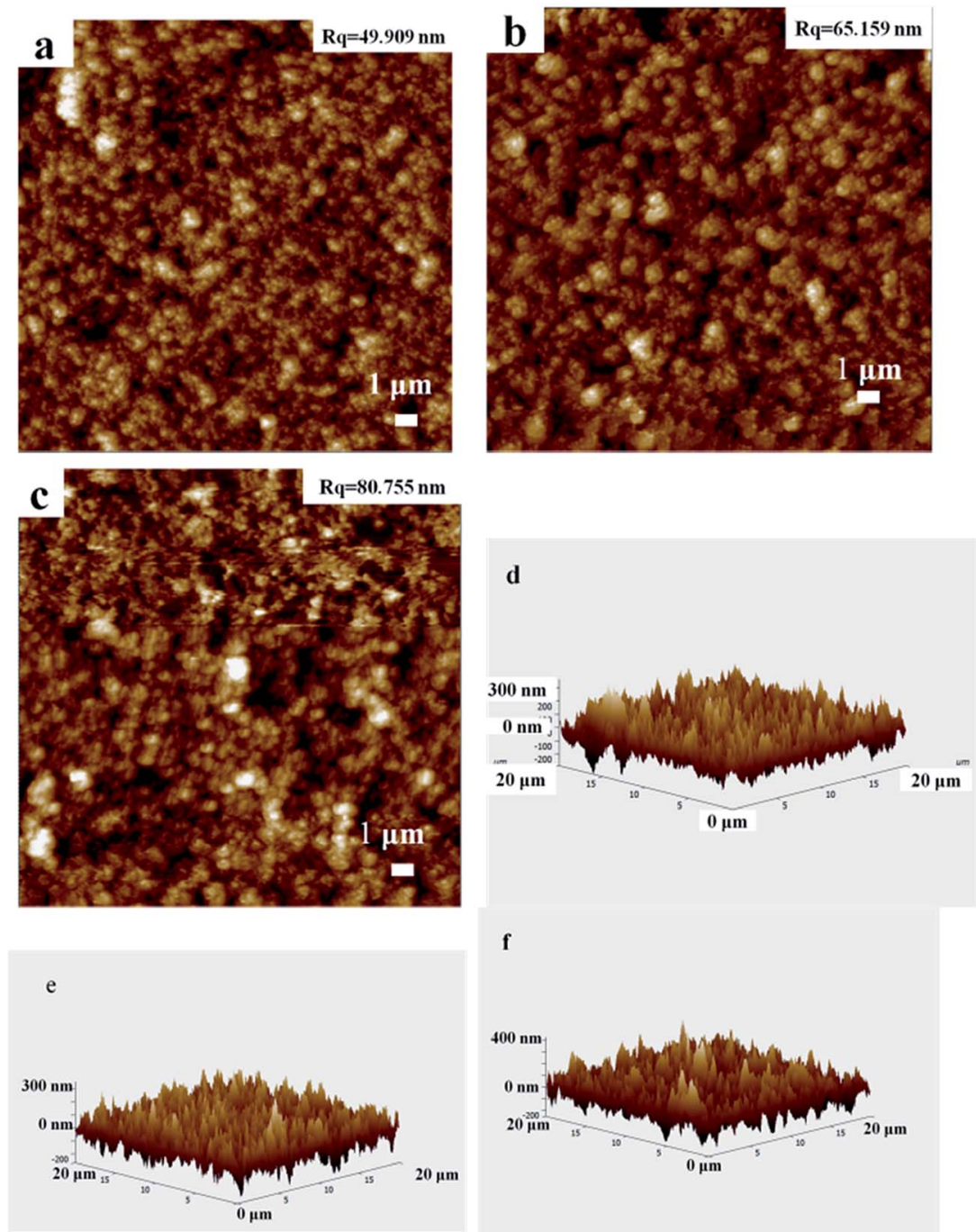

\section{f}

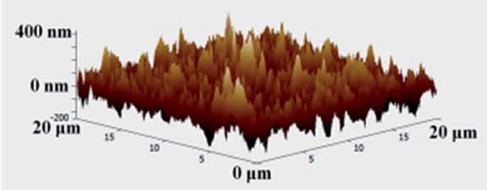

Fig. 5 AFM 2D and 3D image of film obtained by spin coating of $1 \mathrm{wt} \%, 2 \mathrm{wt} \%, 3 \mathrm{wt} \%$ silica nanoparticles-containing solution. (a) $1 \mathrm{wt} \% 2 \mathrm{D}$ image, (b) 2 wt\% 2D image, (c) 3 wt\% 2D image, (d) 1 wt\% 3D image, (e) 2 wt\% 3D image, (f) 3 wt\% 3D image.

where $n$ is the RI of the coating surface, $n_{1}$ is the RI of the solid, and $k$ is the corresponding volume fraction of the solid. From the above equations, when decreasing the volume fraction of the solid, the reflectivity is diminished. The hierarchical composite surface can reduce the reflectance of the glass. ${ }^{44}$ In contrast to the bare glass, the slight decrease in the transmission is due to the light scattering from rough surface. ${ }^{45}$

Table 4 showed the relationship between silica content and roughness, contact angle, and transparency. The roughness of film become more and more bigger, due to the increasing of silica content, which lead to the increasing of contact angle, as well as the decreasing of transparence. However, all the film roughness were below $100 \mathrm{~nm}$, so that all the film has highly transparence.

\subsection{Thermal stability chemical stability of silica-based nanocoating modified by TMCS}

For outdoor application superhydrophobic surfaces, the longterm stability under rigorous conditions is essential. Thus, the temperature stability of the coatings is carried out from -18 to $400{ }^{\circ} \mathrm{C}$ for $2 \mathrm{~h}$. As illustrated in Fig. 8, the samples keep superhydrophobicity with WCA $>150^{\circ}$, demonstrating excellent thermal stability when temperature from -15 to $300{ }^{\circ} \mathrm{C}$, it indicates excellent high-temperature stability of the silica-base surface when the temperature below $300{ }^{\circ} \mathrm{C}$. However, the WCA of the surface decreases a little when the temperature over $300{ }^{\circ} \mathrm{C}$, the WCAs starts to decrease when the temperature ramped up further, and the wettability change to superhydrophilicity after calcination at $400{ }^{\circ} \mathrm{C}$ due to removal of low surface energy material. As expected, when the organic moiety is removed by a thermal treatment in air, the hydrophobic character is irreversibly changed to hydrophilic. When the TMCS modified films are cured at temperatures higher than $350{ }^{\circ} \mathrm{C}$ and $400{ }^{\circ} \mathrm{C}$, this is due to the fact that, above these temperatures the $\mathrm{Si}-\left(\mathrm{CH}_{3}\right)_{3}$ groups get oxidized into $\mathrm{Si}-\mathrm{OH}$ groups which leads to the adsorption of water.

The chemical stability of functional materials is of great significance for application in the aquatics industry. Two 

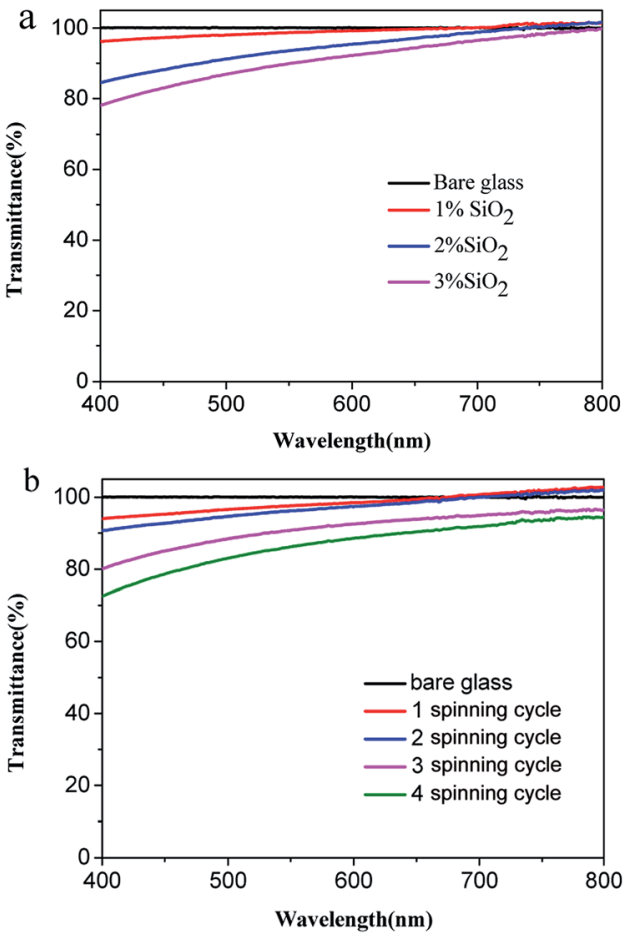

Fig. 6 (a) Optical transmittance spectrums of the various silica-coated glass substrates. (b) Optical transmittance spectrums of the various spinning cycle with $2 \mathrm{wt} \%$ silica-coated glass substrates.

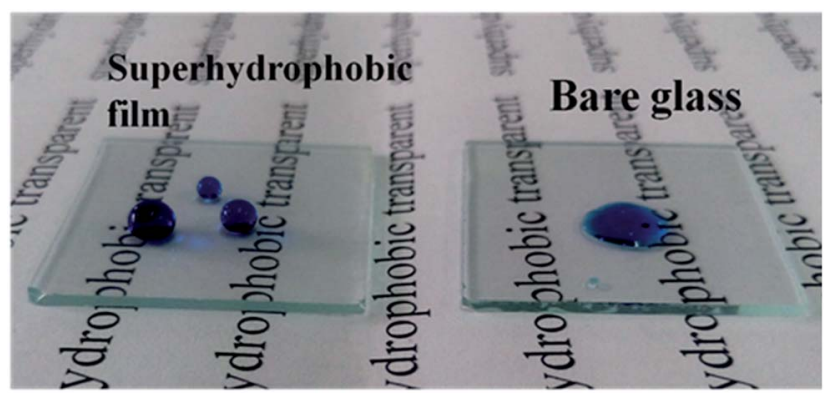

Fig. 7 Image of comparison of superhydrophobic film and bare glass.

measurements are used to evaluate the chemical stability of the as-prepared superhydrophobic glass in an aqueous solution, including acid/alkali corrosion and salt solution immersion. The as-prepared glasses are immersed in an aqueous solution with different $\mathrm{pH}$ values. For the glass immersed in an acid

Table 4 The roughness, contact angle, and (transparency wavelength) at $550 \mathrm{~nm}$ of thin film after coated with different $\mathrm{SiO}_{2}$ content (TMCS silane coupling agent)

\begin{tabular}{lllll}
\hline Sr no. & $\begin{array}{l}\text { Content of } \\
\mathrm{SiO}_{2}[\mathrm{wt}]\end{array}$ & $\begin{array}{l}\text { Roughness } \\
{[\mathrm{nm}]}\end{array}$ & $\begin{array}{l}\text { Contact angle } \\
{\left[{ }^{\circ}\right]}\end{array}$ & $\begin{array}{l}\text { Transparence } \\
\text { at 550 nm [\%] }\end{array}$ \\
\hline 1 & $1 \mathrm{wt} \%$ & $49.909 \mathrm{~nm}$ & $140^{\circ}$ & $98.7 \%$ \\
2 & $2 \mathrm{wt} \%$ & $65.159 \mathrm{~nm}$ & $154^{\circ}$ & $93.5 \%$ \\
3 & $3 \mathrm{wt} \%$ & $80.755 \mathrm{~nm}$ & $164^{\circ}$ & $89.9 \%$
\end{tabular}

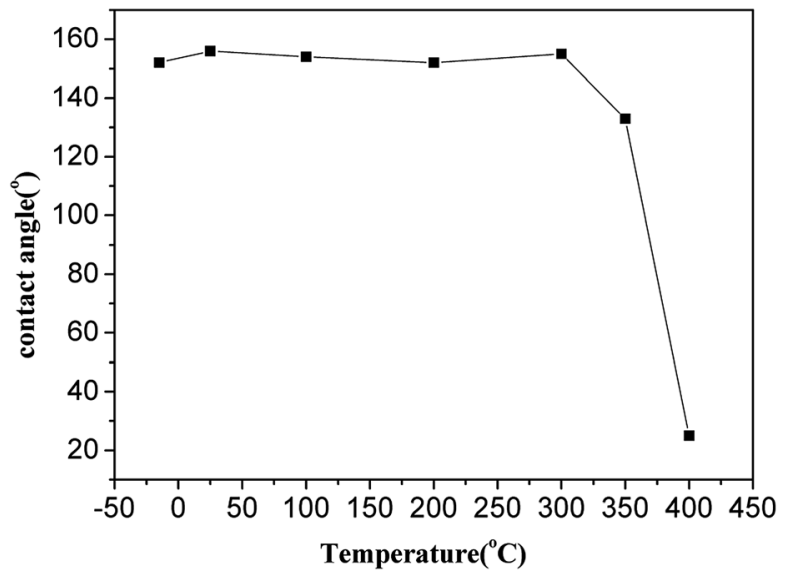

Fig. 8 Dependence of WCAs of the superhydrophobic glass treated from $-15^{\circ} \mathrm{C}$ to $400{ }^{\circ} \mathrm{C}$

solution, the WCA decreases with the increasing of acidity but still maintains hydrophobic performance with WCA over $120^{\circ}$ showed on Fig. 9(a), on the contrary, the WCA of the glass immersed in alkali solution causes obvious deterioration and the superhydrophobicity disappears after immersion in aqueous solution with $\mathrm{pH}$ value over 13 . However, the surface still keep superhydrophobicity with WCA over $150^{\circ}$ after one month of immersion in aqueous solution with $\mathrm{pH}$ value from 4
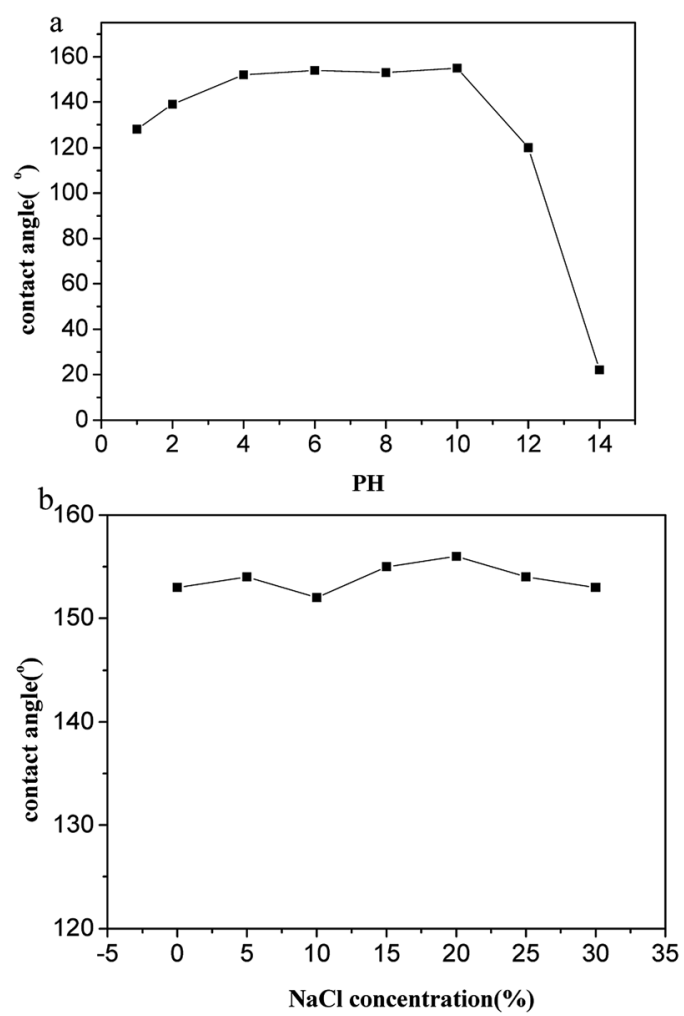

Fig. 9 (a) Variation of WCAs of the superhydrophobic glass after immersing in aqueous solutions with different $\mathrm{pH}$ values for one week. (b) WCAs of the superhydrophobic glass after immersing in $\mathrm{NaCl}$ solutions with concentration from 0 to saturation. 
to 10 . The salt solution stability is tested with the samples immersed in sodium chloride $(\mathrm{NaCl})$ solutions with concentration from 0 to saturation. The WCA is measured to assess the salt tolerance. As showed in Fig. 9(b), no obvious change of WCA is observed after one week immersion and the as-prepared glass keep its superhydrophobicity with WCA $>150^{\circ}$, demonstrating excellent stability to salt solution.

\subsection{Mechanical robustness of the silica-based nanocoating modified by TMCS}

Mechanical robustness is essential for practical applications. However, due to its poor mechanical properties, elaborately designed microstructures of superhydrophobic films are susceptible to damage. Reported in literature, waterfall and sand grain abrasion tests are commonly used to investigate the mechanical robustness of superhydrophobic thin films. ${ }^{\mathbf{4 6 - 4 8}}$ Water flow is applied to impact the superhydrophobic surface from a height of $45 \mathrm{~cm}$ (the velocity is about $4 \mathrm{~m} \mathrm{~s}^{-1}$ ) and a tilt angle of $30^{\circ}$. Fig. 10 shows that the WCA value of the sample decreased with the increasing of water, but keeps the superhydrophobicity with WCA over $150^{\circ}$ up to $20 \mathrm{~L}$ of water (shown on Fig. 10(b) and (c)). A sand impact abrasion test is also performed to investigate the mechanical resistance to sand impact abrasion. $40 \mathrm{~g}$ sand impact abrasion from a $50 \mathrm{~cm}$ height. 100$300 \mu \mathrm{m}$ sized grains have velocity of $8.7 \mathrm{~km} \mathrm{~h}^{-1}$ just before
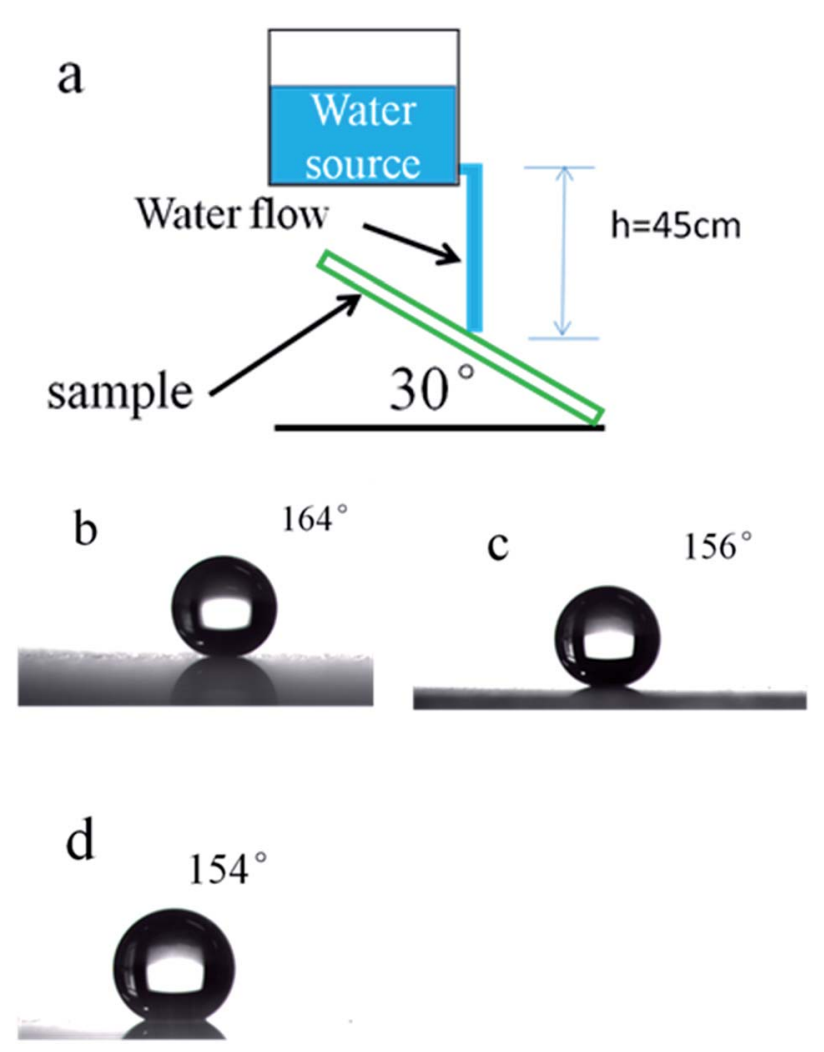

Fig. 10 (a) Schematic diagram of the setup for water impact test from the $45 \mathrm{~cm}$ height. WCAs of the coated glass substrate with $3 \mathrm{wt} \%$ silica solution before (b), and after water impact test from $10 \mathrm{~L}$ water (c), $20 \mathrm{~L}$ water (d), respectively.
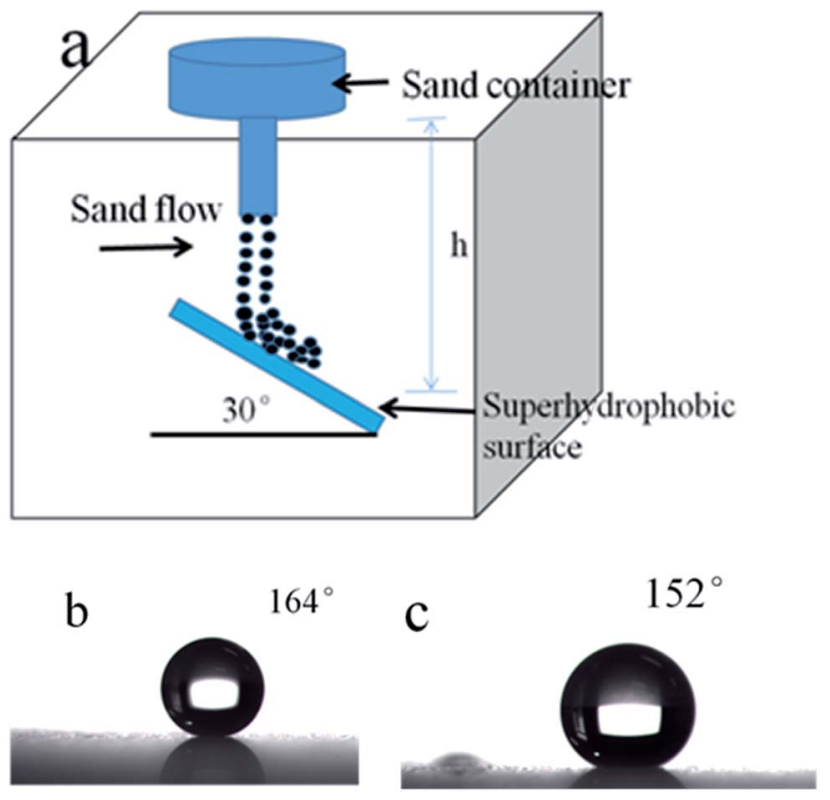

Fig. 11 Mechanical robustness assessed by sand impact abrasion. (a) Sketch of the setup for sand impact abrasion test. WCAs of the coated glass substrate with $3 \mathrm{wt} \%$ silica solution before (b) and after (c) $40 \mathrm{~g}$ sand impact abrasion from a $50 \mathrm{~cm}$ height, $100-300 \mu \mathrm{m}$ sized grains have velocity of the $8.7 \mathrm{~km} \mathrm{~h}^{-1}$ just before impingement.
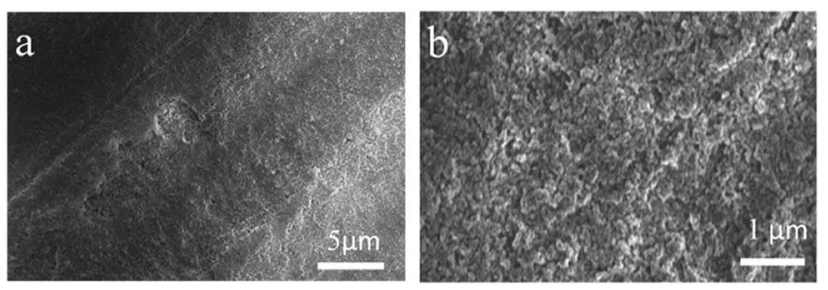

Fig. 12 SEM image of thin film after sand abrasion. (a) Scale bar $5 \mu \mathrm{m}$. (b) Scale bar $100 \mu \mathrm{m}$.

impingement. The WCAs of coated glass substrate before and after sand impact abrasion test are shown in Fig. 11(b) and (c), respectively. After sand impact abrasion, the thin film still shows superhydrophobicity. From Fig. 12(a) we can see, it is noted that the thin film was nearly intact, only few parts of the silica nanoparticles are exposed which had been impinged by sands. The damages may account for the slight decrease in superhydrophobicity. However, the major thin film still shows a micro-nano scale morphology showed on Fig. 12(b), which endows the thin film superhydrophobicity. This very strong adhesion property of the nanocomposite coating are attributed to the fact that hydroxyl groups in the $\mathrm{SiO}_{2}$-coated film interact with the other hydroxyl groups on the surface of the glass substrate.

\section{Conclusion}

We used the hydrolytic properties of tetraethoxysilane hydrolysis to obtain silicic acid as a coupling agent. Dispersion of $\mathrm{SiO}_{2}$ 
nanoparticles in ethanol was performed by ultrasonication. The silica-base coating of nanoscale roughness was coated with the sol-gel method on the glass surface. After being further coated with a low surface energy material TMCS, the silica-based coating was superhydrophobic and transparent. Furthermore, by controlling surface roughness of resultant coatings, it is possible to achieve transparent superhydrophobic coating having excellent wetting behavior properties with high optical transmission, thermal stability, chemical stability and mechanical robustness. The experimental results clearly showed that a simple method such as the sol-gel process resulted in superhydrophobic silica films without using fluoroalkyl compounds at low temperature.

\section{Conflicts of interest}

There are no conflicts to declare.

\section{Acknowledgements}

The work was supported by the key projects of Department of Hubei Provincial Science and Technology (2016AAA034), Natural Science Foundation of Hubei Province (2016CFB507). This work was also supported by the Natural Science Foundation of China (51572072, 51603063 and 21402045).

\section{References}

1 T. S. Wong, S. H. Kang, S. K. Tang, E. J. Smythe, B. D. Hatton, A. Grinthal and J. Aizenberg, Nature, 2011, 477, 443.

2 K. Koch, B. Bhushan, Y. C. Jung and W. Barthlott, Soft Matter, 2009, 5, 1386.

3 X. J. Feng and L. Jiang, Adv. Mater., 2006, 18, 3063.

4 H. Y. Erbil, A. L. Demirel, Y. Avcı and O. Mert, Science, 2003, 299, 1377.

5 M. Ramezani, M. R. Vaezi and A. Kazemzadeh, Appl. Phys. A, 2015, 119, 845.

6 S. Nishimoto and B. Bhushan, RSC Adv., 2013, 3, 671.

7 X. Li and J. He, ACS Appl. Mater. Interfaces, 2012, 4, 2204.

8 J. Zhao, A. Meyer, L. Ma and W. Ming, Chem. Commun., 2013, 49, 11764.

9 Y. Li, X. Zhu, B. Ge, X. Men, P. Li and Z. Zhang, Appl. Phys. A, 2015, 120, 949.

10 B. Ge, X. Zhu, Y. Li, X. Men, P. Li and Z. Zhang, Appl. Phys. A, 2015, 121, 1291.

11 C. Yang, F. Wang, W. Li, J. Ou, C. Li and A. Amirfazli, Appl. Phys. A, 2016, 122, 1.

12 J. Chen, Z. Luo, Q. Fan, J. Lv and J. Wang, Small, 2014, 10, 4693.

13 S. J. Choi and S. Y. Huh, Macromol. Rapid Commun., 2010, 31, 539.

14 S. G. Lee, D. Y. Lee, H. S. Lim, D. H. Lee, S. Lee and K. Cho, Adv. Mater., 2010, 22, 5013.

15 D. Wang, Z. Zhang, Y. Li and C. Xu, ACS Appl. Mater. Interfaces, 2014, 6, 10014.

16 X. Deng, L. Mammen, Y. Zhao, P. Lellig, K. Müllen, C. Li and D. Vollmer, Adv. Mater., 2011, 23, 2962.
17 L. Cao and D. Gao, Faraday Discuss., 2010, 146, 57.

18 S. S. Latthe, C. Terashima, K. Nakata, M. Sakai and A. Fujishima, J. Mater. Chem. A, 2014, 2, 5548.

19 P. Wang, M. Chen, H. Han, X. Fan, Q. Liu and J. Wang, J. Mater. Chem. A, 2016, 4, 7869.

20 H. Yoon, H. Kim, S. S. Latthe, M. W. Kim, S. Al-Deyab and S. S. Yoon, J. Mater. Chem. A, 2015, 3, 11403.

21 Q. Shang and Y. Zhou, Ceram. Interfaces, 2016, 42, 8706.

22 R. G. Karunakaran, C. H. Lu, Z. Zhang and S. Yang, Langmuir, 2011, 27, 4594.

23 L. Xu, R. G. Karunakaran, J. Guo and S. Yang, ACS Appl. Mater. Interfaces, 2012, 4, 1118.

24 X. Deng, L. Mammen, H. J. Butt and D. Vollmer, Science, 2012, 335, 67.

25 A. Nakajima, A. Fujishima, K. Hashimoto and T. Watanabe, ChemInform, 1999, 11, 1365.

26 M. Kim, K. Kim, N. Y. Lee, K. Shin and Y. S. Kim, Chem. Commun., 2007, 22, 2237.

27 A. Nakajima, K. Abe, K. Hashimoto and T. Watanabe, Thin Solid Films, 2000, 376, 140.

28 M. J. Oh, S. Y. Lee and K. H. Paik, J. Ind. Eng. Chem., 2011, 17, 149.

29 L. A. Belyakova and A. M. Varvarin, Colloids Surf., A, 1999, 154, 285.

30 A. J. Howarth, Y. Liu, P. Li, Z. Li, T. C. Wang, J. T. Hupp and O. K. Farha, Nat. Rev. Mater., 2016, 1, 15018.

31 T. A. Makal, X. Wang and H. C. Zhou, Cryst. Growth Des., 2013, 13, 4760.

32 Z. He, M. Ma, X. Lan, F. Chen, K. Wang, H. Deng and Q. Fu, Soft Matter, 2011, 7, 6435.

33 N. Yokoi, K. Manabe, M. Tenjimbayashi and S. Shiratori, ACS Appl. Mater. Interfaces, 2015, 7, 4809.

34 W. H. Huang and C. S. Lin, Appl. Surf. Sci., 2014, 305, 702.

35 J. Cihlár, Colloids Surf., A, 1993, 70, 239.

36 C. J. Brinker, J. Non-Cryst. Solids, 1988, 100, 31.

37 A. V. Rao, M. M. Kulkarni and S. D. Bhagat, J. Colloid Interface Sci., 2005, 285, 413.

38 P. M. Shewale, A. V. Rao and A. P. Rao, Appl. Surf. Sci., 2008, 254, 6902.

39 Y. K. Chen, K. C. Chang, K. Y. Wu, Y. L. Tsai, J. S. Lu and H. Chen, Appl. Surf. Sci., 2009, 255, 8634.

40 G. W. Scherer and C. J. Brinker, Sol-Gel Science: The Physics and Chemistry of Sol-Gel Processing, 1990.

41 N. Hering, S. Kai, R. Riedel, O. Lichtenberger and J. Woltersdorf, Appl. Organomet. Chem., 2001, 15, 879.

42 B. E. Yoldas, Appl. Opt., 1980, 19, 1425.

43 S. Chattopadhyay, Y. F. Huang, Y. J. Jen, A. Ganguly, K. H. Chen and L. C. Chen, Mater. Sci. Eng., R, 2010, 69, 1.

44 K. L. Cho, I. I. Liaw, A. H. F. Wu and R. N. Lamb, J. Phys. Chem. C, 2010, 114, 11228.

45 N. Wang and D. Xiong, Colloids Surf., A, 2014, 446, 8.

46 L. Xu, L. Gao and J. He, RSC Adv., 2012, 2, 12764.

47 D. Ge, L. Yang, Y. Zhang, Y. S. Rahmawan and S. Yang, Part. Part. Syst. Charact., 2014, 31, 811.

48 L. Xu, Z. Geng, J. He and G. Zhou, ACS Appl. Mater. Interfaces, 2014, 6, 9029. 